\title{
Exploring the Pattern of Internal Communication in Total Quality Management Implementation in Manufacturing Companies
}

\author{
Sharina Samsudin ${ }^{1,{ }^{*}}$, Nor Hayati Mohd Jali1 ${ }^{1}$, and Marzura Ibrahim ${ }^{1}$ \\ ${ }^{1}$ Universiti Utara Malaysia, 06010 UUM Sintok, Kedah, Malaysia
}

\begin{abstract}
Communication is an important aspect of organizational dynamic process and it is irrefutable one of the critical success factors of the Total Quality Management (TQM) implementation. Although there are increasing awareness concerning the importance of internal organizational communication, knowledge appears to have rarely translated into practice or there is lack of guidance to effectively practicing it. Therefore, a study was proposed to investigate the pattern of internal communication practice in TQM implementation. This paper concerns on focusing into internal communication practices in TQM implementation factors and the communication patterns in terms of message forms and mediums of communication to convey TQM messages. Reliability and Factor analysis were carried out to confirm items that form each factor in internal communication in TQM implementation. Based on the analysis of survey questionnaires distributed to 104 large manufacturing companies implementing TQM in Malaysia, it was found that there are certain communication patterns practice by the management when conveying and disseminating TQM messages, but they have no specific guidelines. Therefore, the internal communication practices are not well planned. Finally, it is suggested that further research should be carried out to explain clearly the role and strategy of communication on this issue in order to boost the success of TQM implementation particularly in manufacturing company.
\end{abstract}

\section{Introduction}

This paper explores the pattern of internal communication in Total Quality Management (TQM) implementation at manufacturing sector in Malaysia. It aims to provide a significant insight in preparing for a major empirical study in the associated areas.

Communication is fundamentals to any kinds of organized forms of management in organizational context. It concerns the channel, the forms and conventions and the methods or strategies for achieving communication objectives at work. Communication scholars believed that organizational communication strategies are constructed through a permanent relationship that exist between organization and people and also between people themselves [1]. These processes can come from examining communication practices as revealed within

*Corresponding author: sharina@uum.edu.my 
organizational environments, as stated by [2], people create and modify everyday communication strategies based on their interactions, meanings and thoughts while inserting new actors, resources and environments into the process. In fact, effective internal communication gradually will increase employees' trust and commitment, which will lead to employees' engagement [3], and this is very important in successfully implement TQM $[4,5]$.

In the literature of organizational strategy, communication is well known as a functional mechanism of coordination [6]. This means that people communicate with each other in a functional setting, where they practicing the communication strategies either it is planned or unplanned. If it is planned communications, usually, there are some guidelines in organizational situations that tell the employees how they are supposed to act and communicate. Organizations also provide some resources or means of communication, interpersonal and mediated. All these will create a network or chain, a pattern of internal and external communication. Besides, employees also form informal communication networks usually to compensate the weaknesses of formal networks. [7] added that the socalled 'informal' ones, are very substance of organizing. In other situations, choosing the appropriate communication strategies is difficult because the organizational situations sometimes paralyze employees with guidelines or vague information and insufficient resources.

On the other hand, the need for quality improvement continues unabated in both manufacturing and service sectors. In Malaysia, the manufacturing sector learnt some very painful lessons for the past 20 years because of the competition with other developing industrial countries such as Thailand and China, to improve product quality and remain competitive. Malaysia has also taken itself the challenge of attaining the status of a developed nation by the year 2020. Therefore, Malaysia provides an interesting and important area for empirical study of communication in TQM implementation especially in manufacturing sector. This study is limited to large manufacturing companies operating in Peninsula Malaysia that claimed themselves as TQM adopter with at least one ISO certification because empirical studies done on these segment focused on communication within TQM organizations are still very limited.

\section{Literature review}

\subsection{Identity in intercultural communications}

In discussing the role of internal communication, [8] pointed out that, internal communication is crucial for both organizational success and for their day-to-day existence. According to them, this is because internal communication can engage employees' intellectual and creativity to produce value. As [9] mentioned, the role of internal communication is to illuminate the connection between different pieces of information and its job to provide employees with the information they need for their job.

Another issue of internal communication was studied by [10] use a triangulation approach encompassed structured interviews. They adopt the international communication audit questionnaires and a critical incident approach to study the issues of internal communications at Royal Ulster Constabulary (RUC). The result of the interview provided seven categories in terms of how people felt about communication in their sub-division. Among others are, perceived as open to new ideas, willing to share information, able to clarify expectations and able to co-ordinate work. Formal channels as meetings and briefing were perceived as administrative tool and majority indicated a problem in communicating. A little bit difference found by [11] on internal organizational communication. They found 
moderate support for communication within organization towards lean manufacturing implementation making a positive impact on communication primarily involved communication lines with management. They investigated two specific variables; management support and communication within the organization. Additionally, their findings also showed the majority practice poor communication (64.6 percent) involved communications between departments or communication necessary to facilitate material flow through the factory. They also found strong evidence to prove that the dissemination of information to all employees about lean manufacturing did not occur.

In Thailand, [12] studied about the organizational communication pattern at Thaksin University. The study mentioned that the majority of the respondents agreed that the executives should provide clear information, improve public relations through media and declare any problems occurring in any changes to all members of staff. With regard to increase motivation and confidence of workers, supervisors in each department should hold discussions.

On the other hand, TQM has been so popular across industries until [13] mentioned that TQM rank high on the management agenda in the attempt for business to make more profit, improve product quality, increase customers as well as employees' satisfaction and cost reduction. [14] also asserts that TQM not only promotes the performance of all departments but also joins and integrate them to achieve the objectives of the organization. Long before that, [15], have stated that the proper implementation of TQM could be a powerful vehicle where companies are able to achieve excellence in business performance. Therefore, many organizations in manufacturing and services have devoted considerable attention to the implementation of TQM. However, they also claim that companies that have not achieved TQM potential benefits have begun abandoning the practices. The key principles for its failure is the lack of understanding of what TQM means for each unique organization and how to implement it effectively created skepticism on the effectiveness of TQM.

Previous studies showed that many western firms have adopted integrated quality management strategies had not been fully successful $[16,17,18,19]$. If the efforts done without really understand on how it can add to quality improvement, it will just incur the overall production cost. According to [20] one of the causes of failure in implementing TQM is the management of communication strategies are not fully in place. His findings showed that in implementing TQM, organizations should take into consideration the communication elements as well as the management.

Therefore the purpose of this study is to identify and describe the pattern of internal communications at manufacturing organizations in Malaysia in order to help improve the TQM implementation.

\section{Methodology}

This study adapted a survey instrument from European Center for Total Quality Management studied on the Human Resource Management and Total Quality Management relationship. Fifty items related to internal communication were extracted for the purpose of measuring the practice of internal organizational communication in implementing total quality management. These questionnaires were then distributed to identify population using simple random sampling. In this study, 24.3 percent which is 104 companies of the population has responded to the questionnaire distributed, which according to [21] this response rate is similar to other surveys in Malaysia, which usually tend to obtain a response below 20 percent. 


\section{Validity test}

The 50 items selected from the original instrument were then sent to two experts in organizational communications study to be verified for content validity.

Then, factor analysis was applied to reconfirm the internal communication items related to TQM for construct validity test. Factor analysis provides an empirical solution of the variables structure and summarizes the potential dimensions [22]. All 50 items were subjected to the principal component analysis using SPSS version 19. A review of the correlation matrix showed the presence of many coefficients of more than 0.3 and above, which indicated an appropriate data. The Kaiser-Meyer-Olkin value was 0.72 , exceeding the minimum recommended value of 0.6 [23]. The Bartlett's Test of Sphericity reached statistical significance, $\rho<0.05$, supporting the factorability of the correlation matrix.

Secondly, the principal component analysis was performed and shows the presence of 11 components with eigenvalues exceeding 1 . These account for 78.25 percent of the total variance. From these results, a number of components could be retained for the extraction process. Numerous techniques can be applied for determining the number of factors for extraction - eigenvalue exceeding 1, scree plots [22,24] parallel analysis [24], and minimum average partial correlation [25]. In this study, three techniques were applied for the factor extraction, which were the eigenvalue rule, followed by scree plot, and finally parallel analysis. According to [24], this combination for obtaining the result is considered sufficient.

Table 1. The Parallel Analysis Summary Comparing with Principal Component Analysis Eigenvalue

\begin{tabular}{|c|c|c|c|}
\hline Factor number & $\begin{array}{c}\text { Eigenvalue from } \\
\text { principal component } \\
\text { analysis }\end{array}$ & $\begin{array}{c}\text { Random eigenvalue } \\
\text { from parallel analysis }\end{array}$ & Decision \\
\hline 1 & 21.03 & 2.32 & Accepted \\
\hline 2 & 4.28 & 2.21 & Accepted \\
\hline 3 & 4.12 & 2.13 & Accepted \\
\hline 4 & 3.02 & 2.06 & Accepted \\
\hline 5 & 2.26 & 1.93 & Rccepted \\
\hline 6 & 2.02 & 1.82 & Rejected \\
\hline 7 & 1.58 & 1.78 & Rejected \\
\hline 8 & 1.46 & 1.61 & Rejected \\
\hline 9 & 1.23 & 1.59 & Rejected \\
\hline 10 & 1.12 & 1.53 & \\
\hline 11 & 1.08 & & 1.73 \\
\hline
\end{tabular}

In factor analysis, the factor loading shows the weight of each item with the related factors where a higher value of factor loading represent greater underlying meaning for describing the factor. According to [23], variables with a minimum loading of 0.32 are 
acceptable and adequate for interpretation. By referring to the highest loading factor score for each factor, the items were grouped into six factors named, Communication for leadership, Communication for commitment, Communication for customers, Communication for teamwork, Communication for involvement and Communication for training and education.

Therefore, based on the analysis, internal communication items are correlated to these six critical success factors of TQM implementation.

\section{Reliability test}

The internal consistencies of the instrument were analyzed using SPSS version 19 by determining the Cronbach's alpha coefficient. [26] recommended a value above 0.6 for good internal consistencies. Table 1 shows the results of the reliability analysis which shows all Cronbach's alpha coefficient values were above 0.7. It was concluded that the measurement tools were consistent, reliable and usable to be used for data collection survey.

Table 2. Reliability Analysis

\begin{tabular}{|l|c|c|c|}
\hline No & Critical Success Factors & $\begin{array}{c}\text { Number } \\
\text { of Items }\end{array}$ & $\begin{array}{c}\text { Cronbach alpha } \\
\text { coefficient }\end{array}$ \\
\hline 1. & Leadership & 7 & 0.97 \\
\hline 2. & Commitment & 8 & 0.97 \\
\hline 3 & Customer Focus & 8 & 0.98 \\
\hline 4 & Teamwork & 9 & 0.94 \\
\hline 5 & Involvement & 9 & 0.96 \\
\hline 6 & Training & 9 & 0.92 \\
\hline & All items & 50 & 0.97 \\
\hline
\end{tabular}

\section{Pattern of Internal Communication}

There are 56 local companies representing 53.85 percent, 30 eastern companies or 28.85 percent of the total sample while 17.31 percent representing 18 western companies. And, majority of the companies took part employ between 150-499 employees. Most of the representative of the organizations were the middle management level and a member of quality circle of the companies. Thus, these group of employees are qualify and knowledgeable about the subject matter of the study. 
Table 3. Background Profile

\begin{tabular}{|c|c|c|c|}
\hline Items & Profile & Frequency & Percentage \\
\hline 1 & Continent of Origin & & \\
\hline & a. Local & 56 & 53.85 \\
\hline & b. Eastern & 30 & 28.85 \\
\hline & c. Western & 18 & 17.31 \\
\hline 2 & Number of employees & & \\
\hline & a. 150 to 499 & 70 & 67.31 \\
\hline & b. 500 to 999 & 16 & 15.38 \\
\hline & c. 1000 to 1500 & 2 & 15.38 \\
\hline & d. More than 2000 & & \\
\hline 3 & Representatives' position & 17 & 16.35 \\
\hline & a. General Manager/ Senior Manager & 36 & 34.61 \\
\hline & b. HR Manager/ HR Personnel & 28 & 26.92 \\
\hline & c. Quality Manager/Quality Executive & 14 & 13.46 \\
\hline & d. Assistant Manager/Executive & 9 & 8.65 \\
\hline & e. Training Manager & & \\
\hline
\end{tabular}

Table 4 shows that most of the organizations have specific department or section to manage the quality related issues, which was 94.23 percent compared to only 37.5 percent have section in charge of communication related issues.

Table 4. Section In-Charge of Quality and Communication Related Issues

\begin{tabular}{|c|c|c|c|}
\hline Items & Section in-charge of & Frequency & Percentage \\
\hline 1 & Communication & & \\
\hline & a. Yes & 39 & 37.5 \\
\hline & b. No & 65 & 62.5 \\
\hline 2 & Quality & & \\
\hline & a. Yes & 98 & 94.23 \\
\hline & b. No & 6 & 5.77 \\
\hline
\end{tabular}

In terms of interpersonal face-to-face communication practiced in the organizations, the most were formal meetings and briefings and the least were informal discussions. These findings revealed that most of the face-to-face communications practices in the organizations were planned and in the form of top-down flow of communication.

For mediated communication, all the organizations agreed on telephone conversations as the main medium of conversations in the organization, followed very closely by e-mails, letters and memos in the third place, notice boards, newsletters/bulletins and suggestion box. Generally, there were differences in terms of frequencies for interpersonal face-to-face communication and mediated communication (document or electronic) used in disseminating information regarding TQM implementation.

Table 5. Flow of Communication and Communication Medium Used

\begin{tabular}{|c|c|c|c|}
\hline Flow & Medium & Frequency & Percentage \\
\hline Downward & Formal face-to-face meeting & 16 & 15.38 \\
\hline & Informal & 3 & 2.88 \\
\hline & Written & 1 & 0.96 \\
\hline & Telephone & 63 & 60.57 \\
\hline & Emails & 8 & 7.69 \\
\hline & Other: Notice board & 10 & 9.62 \\
\hline
\end{tabular}




\begin{tabular}{|l|c|c|c|}
\hline & Morning prayer & 3 & 2.88 \\
\hline Upward & Formal face-to-face meeting & 8 & 7.69 \\
\hline & Informal & 12 & 11.53 \\
\hline & Written & 23 & 22.11 \\
\hline & Telephone & 42 & 40.38 \\
\hline & Emails & 17 & 14.42 \\
\hline & Other: Suggestions box & 1 & 0.96 \\
\hline Horizontal & Morning prayer & 1 & 0.96 \\
\hline & Formal face-to-face meeting & 5 & 4.81 \\
\hline & Informal & 12 & 11.54 \\
\hline & Written & 30 & 28.85 \\
\hline & Telephone & 44 & 42.30 \\
\hline & Emails & 11 & 10.58 \\
\hline & Other: Online forum & 2 & 1.92 \\
\hline
\end{tabular}

Table 6 shows the types of communication that need improvement. The result shows that all direction of internal communication flow still need improvement.

Table 6: Types of Communication Requires Improvement

\begin{tabular}{|c|c|c|}
\hline & Frequency & Percentage \\
\hline Meetings / Discussions with superior & 10 & 9.62 \\
\hline Meetings / Discussions with subordinate & 12 & 11.54 \\
\hline Meetings / Discussions among peers & 14 & 13.46 \\
\hline Meetings / Discussions inter-dependent & 8 & 7.69 \\
\hline E-Mails & 12 & 11.54 \\
\hline Letters / Memos & 9 & 8.65 \\
\hline Notice boards & 8 & 7.69 \\
\hline Newsletters / Bulletins & 13 & 12.50 \\
\hline Suggestions Boxes & 18 & 17.31 \\
\hline
\end{tabular}

The mean result for the internal organizational communication related to critical success factors (CSFs) of TQM implementations are within the range of four to five (scale is from 1 the least to 6 the most). These findings can be considered as moderate to high except for factor customer focus the mean score is very high. The details of overall mean are presented below:

Table 7. Mean for Degree of Roles of Internal Communication in CSFs (N=104)

\begin{tabular}{|c|c|c|}
\hline No. & CSFs & Mean \\
\hline 1. & Leadership & 4.23 \\
\hline 2. & Commitment & 3.82 \\
\hline 3. & Customer focus & 4.84 \\
\hline 4. & Teamwork & 3.71 \\
\hline 5. & Involvement & 3.66 \\
\hline 6. & Training and education & 3.66 \\
\hline
\end{tabular}

This could indicate that the organizations could still struggling in practicing effective internal organizational communication in the process of implementing TQM except for the 
customer focus and leadership factor where the practice of internal organizational communication in majority of the organizations are already established.

\section{Conclusion}

Although there are consistent answers that the respondents believe internal communication as crucial elements to promote successful TQM implementation but they do not have any guidelines. Companies have provided many types of internal communication channel either for downward, upward or horizontal communication. Anyhow, many still need improvement in terms of the usage and upward flow of communication. Companies should inform and encourage their employees to use and participates in their communication activities.

The respondents agreed that internal communication is one of the core components of TQM implementation. The effectiveness of this core will generate successful leadership, commitment, customer relations, teamwork, training and education and involvement to quality. As mentioned by [27] variables that affected organizational effectiveness most was commitment and satisfaction. Therefore, communication should be included as one of the critical success factors of TQM implementation. And, these then supported by the key management functions of people, processes and procedures, and systems in the organization. All these elements combine and practice together will help increase the success rates of TQM implementation.

More details are needed in order to investigate these findings. Therefore, further study on how communication relates to TQM implementation should be done. In-depth interviews and observations must be carried out to explain clearly on this phenomenon.

\section{References}

1. G. Cheney, L.T. Christensen, T.E. Zorn, S. Ganesh. Organizational Communication in an Age of Globalization: Issues, Reflections, Practices, 2nd.ed, Waveland Press Inc. (2011)

2. M. Marchiori, S. Bulgacov. International Journal of Strategic Communication, 6 (2012)

3. K. E. Mishra, L.Boynton, A.Mishra. International Journal of Business Communication. 51 (2014)

4. J. A. N. Shaari. International Review of Business Research, 6 (2010)

5. F. Talib, Z. Rahman, Identification and Prioritization of Barriers to Total Quality Management Implementation in Service Industry: An Analytic Heirarchy Process Approach. The TQM J., 27 (2015)

6. K. Srikanth \& P. Puranam. Strategic Manage. J (2011)

7. D. K. Mumby, Reframing Difference in Organizational Communication Studies: Research, pedagogy, practice. Thousand Oaks, CA: SAGE (2011)

8. W. R. Kennan, Hazleton, V. Internal Public Relations, Social Capital, and The Role of Effective Organizational Communication (2006)

9. B. Quirke. "Making the Connections: Using Internal Communications to Turn Strategy into Action. Burlington, VT: Gower Publishing Company (2008)

10. D. Quinn \& O. Hargie. An Int. J., 9. 2 (2004)

11. J. M. Worley \& T. L. Doolen. The Role of Communication and Management Support in a Lean Manufacturing Implementation. Management Decision, 44, 2 (2006)

12. C. Noknoi. Eur. J. Sci. Res. 80, 4 (2012)

13. M. Kolaikuntla, A Research Study on Estimation of TQM 'Factors Ratings' Through Analytical Hierarchy Process. Procedia Economics and Finance, 3, (2012)

14. A. Brun. Int. J. Prod. Econ., 131, 1 (2011)

15. D. K. Shin \& G. A. El-Enein. Critical Implementation Issues in Total Quality Management. S.A.M. Advance Management Journal, 63, 1 (1998) 
16. Z. Huq \& T.N. Martin. Workforce cultural factors in TQM/CQI Implementation in Hospitals. Health Care Manage. R., 25(3), 80-93 (2000)

17. G. Polat, A. Damci, \& Y. Tatar. Barriers and Benefits of Total Quality Management in the Construction Industry: Evidence from Turkish Contractors. 7th Research/Expert Conference with International Participations (2011)

18. Tey Lian Seng and Ooi Teck Loon. Research Journal of Applied Sciences, Engineering and Technology. 7, 16 (2014)

19. A. M. Mosadeghrad. Int J Qual Health Care, 26, 2 (2013)

20. Gathalian. People Empowerment: The Key to TQM Success. In The TQM Magazine, 9(6), 429433 (1997)

21. M. Othman. Penulisan Tesis dalam Bidang Sains Sosial Terapan. Serdang:Penerbit Universiti Putra Malaysia (2001)

22. J.F.J. Hair, R.E. Anderson, R.L. Tatham, W.C. Black. Multivariate analysis, 5 (1998)

23. B.G. Tabachnick, L.S. Fidell, Using Multivariate Statistics, Pearson, 6 (2013)

24. J. Pallant, SPSS Survival Manual, 12 (2005)

25. E. Ferguson \& T. Cox. Int. J. Select. Assess.,1, 2 (1993)

26. U. Sekaran. Research Methods For Business: A Skill Building approach. $3^{\text {rd }}$.ed. USA: Hermitage Publishing (2000)

27. R. Mohammed. Organization-Public Relationships Practices in University Setting. The International Conference on Communication \& Media (i-COME'14) 2014 